\title{
CLINICAL PROFILE OF ETHANOL-RELATED COMPLICATIONS IN AN ICU SETUP IN A TERTIARY HOSPITAL AT CHENNAI
}

\author{
Poongavanam Paranthaman ${ }^{1}$, Ponnusamy Raja², Shaikh Sulaiman Meeran ${ }^{3}$, Thenrajan Balaji ${ }^{4}$, Abhijeet P. Lakhamawad 5 \\ 1Professor, Department of General Medicine, Kilpauk Medical College \& GRH, Chennai. \\ ${ }^{2}$ Assistant Professor, Department of General Medicine, Kilpauk Medical College \& GRH, Chennai. \\ 3 Professor, Department of General Medicine, Kilpauk Medical College \& GRH, Chennai. \\ ${ }^{4}$ Assistant Professor, Department of General Medicine, Kilpauk Medical College \& GRH, Chennai. \\ 5Postgraduate Student, Department of General Medicine, Kilpauk Medical College \& GRH, Chennai.
}

\section{ABSTRACT}

\section{BACKGROUND}

Alcohol consumption is more common across subpopulations of South India. But the complications associated with alcohol consumption varies across the groups including those defined by age and gender of patient, amount, duration, brand of the alcohol used by the patient. Epidemiological survey conducted across world found that young adults (18 to 25) are at high risk of complications. With respect to gender, men reported more alcohol consumption and binge drinking than women.

\section{MATERIALS AND METHODS}

All patients with history of alcohol consumption admitted in ICU of Government Royapettah Hospital, Chennai were assessed and followed up from July 2016 to Feb 2017. The diagnosis was made based on the clinical presentation such as ascites, jaundice, upper GI bleed, hepatic encephalopathy, Wernicke's encephalopathy with respect to age, sex, amount and duration of alcohol consumption.

\section{RESULTS}

Out of 52 patients in our study, 2 (3.8\%) were female and remaining 50 (96.2\%) were male. The higher incidence of complications was in the age group 40-59 yrs., which constituted 33 cases (63\%), followed by 20-39 yrs. constituted 17 cases (33\%). The least incidence was observed in the age group $>60$ yrs., 2 cases (4\%). The incidence of complications observed in our study were symptomatic liver cirrhosis with minor complications (31\%), upper GI bleeding (27\%), hepatic encephalopathy (13\%), Wernicke's encephalopathy (13\%), seizures (12\%), hypoglycaemia (4\%).

\section{CONCLUSION}

We observed that there is an increase in incidence of alcohol-related complications in younger age group. Acute complications without liver cirrhosis like UGI bleed due to erosive gastritis, Wernicke's encephalopathy, seizures and hypoglycaemia were more with those who consumed large quantity of alcohol. Acute-on-chronic complications like UGI bleed secondary to liver cirrhosis and hepatic encephalopathy were directly proportional to duration of alcohol ingestion. In our study, we found that there is transition of acute alcohol-related complications from middle and older age group to younger age group. Hence, proper health education, legislation, early identification and treatment will decrease the morbidity and mortality due to acute alcohol-related complications.

\section{KEYWORDS}

Alcoholism, Upper GI Bleed, Hepatic Encephalopathy, Hypoglycaemia, Cirrhosis.

HOW TO CITE THIS ARTICLE: Paranthaman P, Raja P, Meeran SS, et al. Clinical profile of ethanol-related complications in an ICU setup in a tertiary hospital at Chennai. J. Evolution Med. Dent. Sci. 2017;6(51):3906-3910, DOI: 10.14260/Jemds/2017/845

\section{BACKGROUND}

Liver is the main organ responsible for metabolism of ethanol. Stomach also contributes to some extent for its metabolism. The major enzymes involved in ethanol metabolism are alcohol dehydrogenase (ADH), cytochrome p450 2E1 (CYP2C1), catalase.[1] Ethanol is converted into acetaldehyde by ADH and CYP2C1. Acetaldehyde is converted into acetoacetate by aldehyde dehydrogenase (ALDH). Main compound responsible for systemic toxic effect of ethanol is acetaldehyde. Systemic effects include nausea, flushing and

Financial or Other, Competing Interest: None.

Submission 08-05-2017, Peer Review 14-06-2017,

Acceptance 20-06-2017, Published 24-06-2017.

Corresponding Author:

Dr. Poongavanam Paranthaman,

Professor,

Department of General Medicine,

Government Royapettah Hospital, Chennai.

E-mail: paranthaman1964@rediffmail.com

DOI: $10.14260 /$ jemds $/ 2017 / 845$

(c) headache. Acetaldehyde by combining with reactive residues on protein of hepatocytes form adducts and it leads to modification of hepatocyte. This modified molecule is responsible for autoimmune like manifestations. Various other mechanisms by which ethanol causes liver damage includes oxidative stress, mitochondrial dysfunction, impaired proteasome function, hypoxia.

Common complications of ethanol include liver cirrhosis, upper GI bleeding, hepatic encephalopathy, Wernicke's encephalopathy, hypoglycaemia, seizures.

Liver cirrhosis may be diagnosed with clinical history like nausea, vomiting, weight loss, weakness, fever, diarrhoea, abdominal pain. Examination includes jaundice, ascites, hepatomegaly, splenomegaly, hepatic tenderness, peripheral oedema, spider angioma. Some patients can present with muscle wasting, palmar erythema, Dupuytren's contracture. Lab findings include increase in aspartate transaminase (AST) and alanine transaminase (ALT). AST/ALT $>2$ is characteristic of alcohol-related disease. Management is mainly abstinence from alcohol and lifestyle modification. 
Treatment includes anticytokine drugs like non-selective phosphodiesterase inhibitors such as Pentoxyphylline. Low amount of TNF is required for liver regeneration, so TNF alpha inhibitors are not preferred.

Hepatic encephalopathy results from increase in serum ammonia due to hepatocyte dysfunction caused by cirrhosis of liver. Ammonia is required for conversion of glutamate to glutamine in astrocytes. So more glutamate is formed because of more ammonia in brain. Glutamine is an osmotically active compound which causes astrocyte swelling and brain oedema which leads to impaired neurotransmission. So main treatment of hepatic encephalopathy is to washout ammonia from the body. Various measures to washout the ammonia from the body includes bowel wash, gut antibiotics like rifaximin, lactulose and LOLA (L-ornithine-L-aspartate).

Upper GI bleeding caused by portal hypertension is variceal bleeding. Upper GI endoscopy is used to diagnose it. Endoscopy is repeated in 1 to 2 yrs. if small varices are detected. For those who are not fit for upper GI endoscopy, wireless video capsule endoscopy and CT imaging can be used.

Wernicke's encephalopathy occurs because of thiamine deficiency in chronic alcoholics due to impaired thiamine absorption. It is characterised mainly by ataxia, confusion and ophthalmoplegia. It is treated with intravenous or intramuscular thiamine.

\section{Objective}

To study the frequency of complications among acute alcoholrelated admissions in ICU.

\section{MATERIALS AND METHODS}

It is a descriptive study conducted in intensive care unit of Government Royapettah Hospital, Chennai over a period of 8 months from July 2016 to Feb 2017 with acute alcoholrelated complications. Diagnosis was made based on clinical symptoms and signs related to acute alcohol ingestion and related complications.

\section{Inclusion Criteria}

All patients with history of alcohol consumption who required intensive care. Both male and female sex were included.

\section{Exclusion Criteria}

Patients with acute alcohol-related complications with comorbidities like diabetes mellitus, systemic hypertension, dyslipidaemia, drug abuse, bronchial asthma coronary artery disease, chronic kidney disease were excluded from study.

Alcoholic patients with suspected liver disease who had abdominal ultrasonographic characteristic of cirrhosis (Nodular surface of liver, heterogeneity of liver parenchyma or liver atrophy) and with lab features consistent with cirrhosis (Low serum albumin and low platelet) were assessed for decompensation. Decompensation was defined by the presence of either ascites, pedal oedema, hepatic encephalopathy, variceal bleeding. Presence of oesophageal varices were confirmed by upper GI endoscopy in those who presented with upper GI bleed. To support the clinical diagnosis alcohol-related cirrhosis and the magnitude of decompensation, blood investigations were done. Various blood test includes liver function test, complete blood count and renal function test. Those who presented with hypoglycaemic coma, diagnosis established with capillary blood glucose of less than $70 \mathrm{mg} / \mathrm{dL}$. History regarding the amount and duration of alcohol consumption was taken from the patient. Those who presented with altered sensorium, information regarding the amount and duration of alcohol consumption is taken from the relative of the patient.

\section{Study Design}

We have recruited patients with acute alcohol-related complications admitted in ICU of Government Royapettah Hospital over a period of July 2016 to February 2017. Majority of complications were UGI bleed, hepatic encephalopathy, cirrhosis with minor complications like breathlessness, ascites, pedal oedema, Wernicke's encephalopathy, hypoglycaemia and seizures. Each case history including the amount and duration of alcohol consumption was taken and detailed examination done. Data regarding the age, sex, amount and duration of alcohol consumption, presenting complaints and vitals were recorded and analysed.

\section{RESULTS}

Total 52 patients with acute alcohol-related complications requiring intensive care were recruited. Characteristics of study group is described below.

\section{Age group wise distribution}

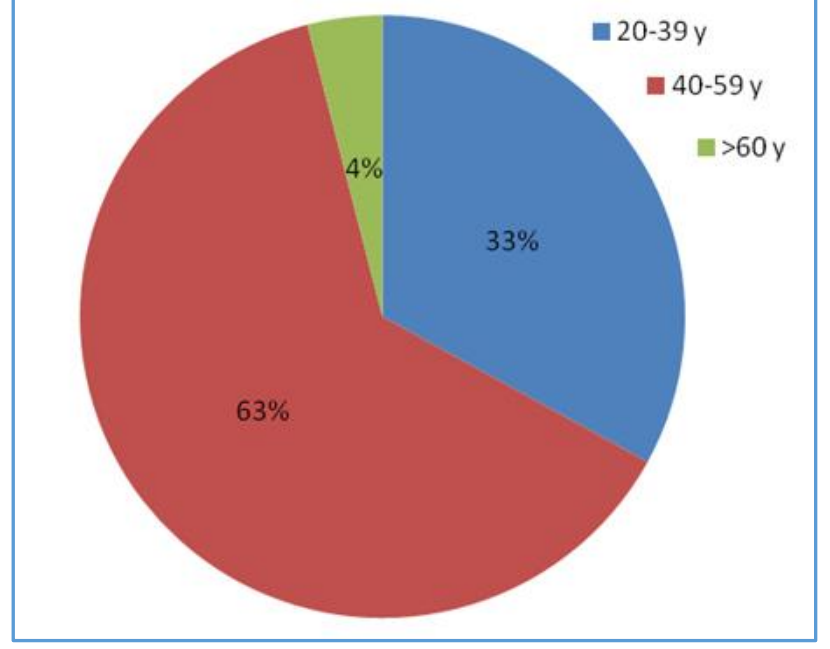

Figure 1. Age Group wise Distribution

We have divided all patients into 3 groups. Age group includes 20-39 yrs., 40-59 yrs. and >60 yrs. Maximum number of patients were in the age group of 40-59 yrs. which is the most productive age group which constituted 63\% (33 cases) followed by young age 20-39 yrs. which is a more crucial period of life which constituted 33\%(17 cases). We have included female sex also which constituted 2 out of 52 . Females belong to age group 20-39 yrs. and 40-59 yrs. Incidence of females were very less because of social stigma and cultural customs. Out of 2 females, one developed DCLD with UGI bleed and another one developed DCLD with minor complication. Both were taking less quantity and duration of alcohol abuse was less than the age-matched male group. This indicates females are more prone for complications even with lesser amount of alcohol consumption as mentioned in literature, secondary to increased alcohol dehydrogenase enzyme activity in female. 


\begin{tabular}{|c|c|c|c|c|c|}
\hline $\begin{array}{c}\text { Symptomatic DCLD } \\
\text { with Minor } \\
\text { Complications }\end{array}$ & $\begin{array}{c}\text { DCLD with } \\
\text { Complications HE, UGI } \\
\text { bleed }\end{array}$ & $\begin{array}{c}\text { UGI Bleed without } \\
\text { DCLD }\end{array}$ & $\begin{array}{c}\text { Wernicke's } \\
\text { Encephalopathy }\end{array}$ & Seizures & Hypoglycaemia \\
\hline $16(31 \%)$ & $7(13 \%) 7(13 \%)$ & $7(13 \%)$ & $7(13 \%)$ & $6(12 \%)$ & $2(4 \%)$ \\
\hline \multicolumn{4}{|c|}{ Table 1. Proportion of the Patients with Different Complications } \\
\hline
\end{tabular}

HE: hepatic encephalopathy, WE: Wernicke's encephalopathy, DCLD: decompensated liver disease.

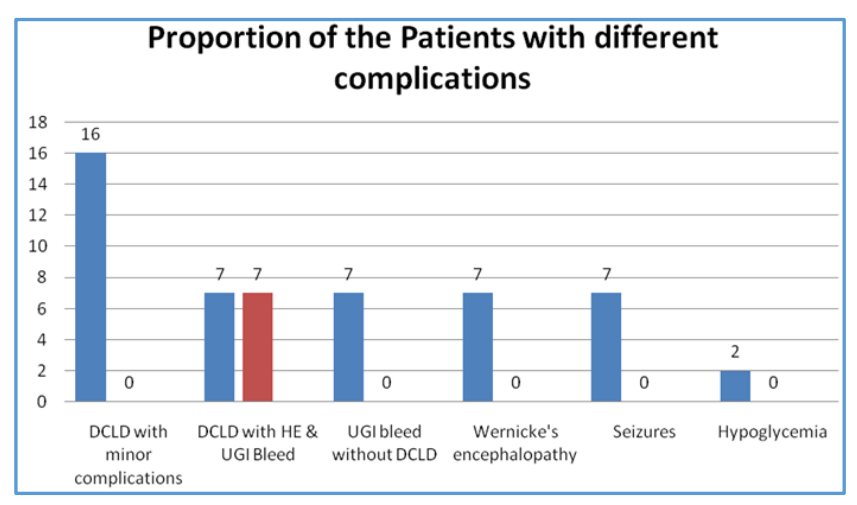

Figure 2. Proportion of Patients with Different Complications

We also categorised patients based on the complications such as DCLD with minor complications which constituted $16 \%$ which is the most common complication followed by DCLD with hepatic encephalopathy and UGI bleed which constituted 7\% respectively. But UGI bleed without DCLD due to erosive gastritis was also $7 \%$. Percentage of Wernicke's encephalopathy and seizures was $7 \%$ and these complications were observed in younger patients with lesser duration of alcohol consumption in comparison to UGI bleed and hepatic encephalopathy which occurred in patients with alcohol consumption of moderate-to-large quantity with longer duration. But incidence of hypoglycaemic coma was $4 \%$ which recovered immediately with intravenous dextrose infusion.

Various ethanol-related complications include: 1) Decompensated liver disease with minor complications like ascites, breathlessness and peripheral oedema. 2) Upper GI bleeding due to erosive gastritis. 3) Upper GI bleeding secondary to DCLD. 4) Hepatic encephalopathy. 5) Wernicke's encephalopathy. 6) Seizures. 7) Hypoglycaemia. Maximum patients (31\%) were found to have symptomatic DCLD with minor complications like breathlessness, ascites and peripheral oedema; upper GI bleed 7\%; hepatic encephalopathy 7\%; Wernicke's encephalopathy $13 \%$ (7 cases); seizures $12 \%$ (6 cases) and hypoglycaemia $4 \%$ (2 cases). Among the 40-60 years age group, which included 33 patients, 14 had symptomatic DCLD with minor complications, while 6 had hepatic encephalopathy, 4 had UGI bleed with DCLD and 4 had UGI bleed without DCLD. 4 patients in this group developed Wernicke's encephalopathy. Seizures were more common in the younger age group viz. 20-39 years. There was only one case of symptomatic DCLD with minor complications in the younger age group; however, 3 cases of UGI bleed in the group had associated DCLD. There were 3 patients admitted with UGI bleed without DCLD in the same age group. There was no case of hepatic encephalopathy in this age group. Wernicke's encephalopathy was not rare in the age group too, with 3 cases recorded. In the elderly population (age $>60$ ), which constituted a minority of the total patients, symptomatic DCLD with minor complications, hepatic encephalopathy and hypoglycaemia were seen (Table 2).

Quantity and number of years of alcohol consumption were also observed. 23 patients fell in to the group of $10-20$ years of alcohol consumption. Symptomatic DCLD with minor complications, UGI bleed associated with DCLD and Wernicke's encephalopathy were found mainly in this group. Patients with history of alcohol intake for 5-10 years also were 23 in number; however, symptomatic DCLD with minor complications was found majorly in them. UGI bleed without DCLD and seizures were also not found to be uncommon in the group. In patients with a short history of alcohol intake, that is less than 5 years, the complications were minimal except for 1 case of Wernicke's encephalopathy. In the group with history of alcohol intake for more than 20 years, symptomatic DCLD with minor complications, UGI bleed with DCLD and hypoglycaemia were found (Table 3). Patients with history of consumption of more than $360 \mathrm{~mL}$ of alcohol per day showed symptomatic DCLD with minor complications, UGI bleed and hepatic encephalopathy. However, patients with history of consumption of 180-360 mL of alcohol per day, who were maximum in number, showed a variety of complications. 3 patients developed UGI bleed with DCLD, 2 developed UGI bleed without DCLD, 2 developed hepatic encephalopathy while 4 patients had Wernicke's encephalopathy and 5 patients were found to have seizures in this group. Symptomatic DCLD with minor complications was the major contributor in the less than $180 \mathrm{~mL}$ per day group with a total of 10 patients. Other complications like UGI bleed with DCLD (2 cases), seizures (2 cases), hypoglycaemia (1 case) and Wernicke's encephalopathy ( 2 cases) were also found. 4 patients in the group developed DCLD with hepatic encephalopathy (Table 4).

\begin{tabular}{|c|c|c|c|c|}
\hline & $\begin{array}{c}20-39 \\
\text { yrs. }\end{array}$ & $\begin{array}{c}40-60 \\
\text { yrs. }\end{array}$ & $\begin{array}{l}>60 \\
\text { yrs. }\end{array}$ & Total \\
\hline $\begin{array}{l}\text { Symptomatic DCLD with } \\
\text { minor complications }\end{array}$ & 1 & 14 & 1 & 16 \\
\hline DCLD with UGI bleed & 3 & 4 & 0 & 7 \\
\hline $\begin{array}{l}\text { DCLD with hepatic } \\
\text { encephalopathy }\end{array}$ & 0 & 6 & 1 & 7 \\
\hline UGI bleed without DCLD & 3 & 4 & 0 & 7 \\
\hline $\begin{array}{c}\text { Wernicke's } \\
\text { encephalopathy }\end{array}$ & 3 & 4 & 0 & 7 \\
\hline Seizures & 6 & 0 & 0 & 6 \\
\hline Hypoglycaemia & 1 & 0 & 1 & 2 \\
\hline
\end{tabular}




\begin{tabular}{|c|c|c|c|c|c|}
\hline $\begin{array}{c}\text { Alcohol-related } \\
\text { complications }\end{array}$ & $<\mathbf{5}$ yrs. & $\begin{array}{c}\mathbf{5 - 1 0} \\
\text { yrs. }\end{array}$ & $\begin{array}{c}\mathbf{1 0 - 2 0} \\
\text { yrs. }\end{array}$ & $\begin{array}{c}\mathbf{> 2 0} \\
\text { yrs. }\end{array}$ & Total \\
\hline $\begin{array}{c}\text { Symptomatic } \\
\text { DCLD with minor } \\
\text { complications }\end{array}$ & 0 & $9(17 \%)$ & $5(10 \%)$ & $2(4 \%)$ & $16(31 \%)$ \\
\hline $\begin{array}{c}\text { DCLD with UGI } \\
\text { bleed }\end{array}$ & 0 & $2(4 \%)$ & $5(10 \%)$ & 0 & $7(13 \%)$ \\
\hline $\begin{array}{c}\text { DCLD with } \\
\text { hepatic } \\
\text { encephalopathy }\end{array}$ & 0 & $2(4 \%)$ & $4(8 \%)$ & $1(2 \%)$ & $7(13 \%)$ \\
\hline $\begin{array}{c}\text { UGI bleed } \\
\text { without DCLD }\end{array}$ & 0 & $5(10 \%)$ & $2(4 \%)$ & 0 & $7(13 \%)$ \\
\hline $\begin{array}{c}\text { Wernicke's } \\
\text { encephalopathy }\end{array}$ & $1(2 \%)$ & 0 & $6(12 \%)$ & 0 & $7(13 \%)$ \\
\hline Seizures & 0 & $5(10 \%)$ & $1(2 \%)$ & 0 & $6(12 \%)$ \\
\hline Hypoglycaemia & 0 & $1(2 \%)$ & 0 & $1(2 \%)$ & $2(4 \%)$ \\
\hline \multicolumn{7}{|c|}{ Table 3. Duration of Consumption of Alcohol } \\
\hline
\end{tabular}

Patients with DCLD and hepatic encephalopathy had higher duration of alcohol consumption.

\begin{tabular}{|c|c|c|c|}
\hline & $<180 \mathrm{~mL}$ & $180-360 \mathrm{~mL}$ & $>360 \mathrm{~mL}$ \\
\hline \begin{tabular}{|c|} 
Symptomatic DCLD \\
with minor \\
complications
\end{tabular} & $10(20 \%)$ & $5(10 \%)$ & $1(2 \%)$ \\
\hline $\begin{array}{c}\text { DCLD with UGI } \\
\text { bleed }\end{array}$ & $2(4 \%)$ & $3(6 \%)$ & $2(4 \%)$ \\
\hline DCLD with HE & $4(8 \%)$ & $2(4 \%)$ & $1(2 \%)$ \\
\hline $\begin{array}{l}\text { UGI bleed without } \\
\text { DCLD }\end{array}$ & 0 & $2(4 \%)$ & $5(10 \%)$ \\
\hline $\begin{array}{c}\text { Wernicke's } \\
\text { encephalopathy }\end{array}$ & $2(4 \%)$ & $4(8 \%)$ & $1(2 \%)$ \\
\hline Seizures & $1(2 \%)$ & $5(10 \%)$ & 0 \\
\hline Hypoglycaemia & $2(4 \%)$ & 0 & 0 \\
\hline Table 4. Qua & $\begin{array}{r}\text { Cof Alco } \\
\text { Compli }\end{array}$ & $\begin{array}{l}\text { Consumpti } \\
\text { ion }\end{array}$ & n each \\
\hline
\end{tabular}

Patients with complications like UGI bleed without DCLD, Wernicke's encephalopathy, seizures had higher quantity of alcohol consumption.

\section{DISCUSSION}

Out of 52 patients in our study, majority were male (50) which constituted $96.2 \%$ and 2 were female (3.8\%) unlike study carried out in Uganda where the proportion of males and females were almost equal.[2] Binge drinking was more in males in a study conducted by Delker E et al [3] as observed in our study. Alcohol-related complications were more among the age group 40-59 yrs., 33 cases (66\%), which is a more productive age group followed by younger age group 20-39 yrs., 17 cases (33\%), which is a most crucial period of life. However, alcohol consumption in female was less and complications which occurred were associated with lesser duration and quantity of alcohol which is possibly related to social and cultural customs of particular region. We also observed younger alcoholics with more severe complications. Youngest age group in our study was 23 yrs. who started taking alcohol at the age of 13 yrs. which was uncommon before. Young patients who started consuming alcohol at an early age had more fulminant form of UGI bleed without DCLD than those that started alcohol consumption at a later age who developed UGI bleed secondary to DCLD. The mortality rates were more with UGI bleed due to DCLD than without DCLD. We also observed in our study that Wernicke's encephalopathy and seizure disorder were not associated with DCLD, but they recovered completely without complication. The incidence of hypoglycaemic coma constituted the lowest percentage (4\%) in our study compared to earlier observations.

In a study conducted in North East India, younger age group was found to have more incidence of alcoholic cirrhosis and predominantly in males. ${ }^{[4]}$ We also observed that more duration of alcohol consumption is associated with DCLD related complications like UGI bleed secondary to DCLD and hepatic encephalopathy. Acute complications without cirrhosis like UGI bleed due to erosive gastritis, Wernicke's encephalopathy, seizures were directly proportional to quantity of alcohol consumption. In a study conducted by Mossawa JF et al in Basra, it was found that percentage of people who consumed more than $750 \mathrm{~mL}$ of alcohol per day were $53 \%[5]$ whereas in our study people who consumed more than $380 \mathrm{~mL}$ were $20 \%$.

Patients with alcohol consumption at younger age developed acute-on-chronic complications like hepatic encephalopathy, DCLD at younger age.

We lately observed that increased incidence of acute alcohol-related complications are more with younger age group probably due to easy accessibility, availability and affordability. So if measures are taken to address the above issues, we can prevent morbidity and mortality and also improve the quality of life.

There is transition in occurrence of alcohol-related complications from middle age group 40-59 yrs. (66\%) to younger age group 20-39 yrs. (33\%). Overall mortality was high due to acute-on-chronic complications like UGI bleed due to liver cirrhosis and hepatic encephalopathy which constituted 2 out of 4 deaths which occurred in our study and other 2 died of massive upper GI bleed with haemodynamic instability at the time of admission.

\section{CONCLUSION}

Acute alcohol-related complications like UGI bleed due to erosive gastritis, Wernicke's encephalopathy, seizures were more with large quantity and shorter duration of alcohol consumption. Acute-on-chronic complications like UGI bleed due to DCLD and hepatic encephalopathy are associated with longer duration and moderate-to-large quantity of alcohol consumption. There is a transition in occurrence of acute alcohol-related complications from middle and older age to younger age. Hence, adequate education about hazardous effects of alcohol consumption, legislation, early diagnosis and treatment will decrease the morbidity and mortality due to alcohol in future.

\section{REFERENCES}

[1] Yip WW, Burt AD. Alcoholic liver disease. Semin Diagn Pathol 2006;23(3-4):149-60. 
[2] Apica BS, Ocama P, Seremba E, et al. Decompensated cirrhosis-related admissions in a large urban hospital in Uganda: prevalence, clinical and laboratory features and implications for planning patient management. African Health Sciences 2013;13(4):927-32.

[3] Delker E, Brown Q, Hasin DS. Alcohol consumption in demographic subpopulations: an epidemiologic overview. Alcohol Res 2016;38(1):7-15.
[4] Bhattacharyya M, Barman NN, Goswami B. Survey of alcohol-related cirrhosis at a tertiary care center in North East India. Indian J Gastroenterol 2016;35(3): 167-72.

[5] Mossawe JF, Ali NA, Ahmed JH, et al. Clinical and biochemical profile of alcohol users in Basra. East Mediterr Health J 2009;15(5):1226-34. 